(c) American Dairy Science Association, 2007.

\title{
Comparison of the Behavior of Two Nanofiltration Membranes for Sweet Whey Demineralization
}

\author{
B. Cuartas-Uribe, ${ }^{1}$ M. I. Alcaina-Miranda, E. Soriano-Costa, and A. Bes-Piá \\ Department of Chemical and Nuclear Engineering, Polytechnic University of Valencia, Valencia 46022, Spain
}

\begin{abstract}
Nanofiltration is a process used to separate mineral salts from lactose, having previously removed the proteins by ultrafiltration. Both proteins and lactose can be used as raw materials to prepare a variety of products. In this paper, we studied the feasibility of demineralizing sweet whey obtained from the cheese industry of the Comunidad Valenciana (Spain) using membrane technologies. The NF200 membrane showed the highest volumetric flux and solute rejection values, whereas the DS-5 DL membrane showed the lowest values. The volumetric fluxes obtained with the NF200 and DS-5 DL membranes in these experiments with the ultrafiltered whey demonstrated significant differences between membranes. Concerning solute rejection, the highest values were obtained using the NF200 membrane. The chosen parameter to evaluate the demineralization capability was solute flux. In this way, the values obtained for chloride ion were 9.90 and $32.42 \mathrm{~g} /$ $\left(\mathrm{m}^{2} \cdot \mathrm{h}\right)$ for the NF200 and DS-5 DL membranes, respectively, with the highest demineralization rates being achieved with the DS-5 DL membrane.
\end{abstract}

Key words: nanofiltration, sweet whey, demineralization, lactose

\section{INTRODUCTION}

Many membrane technologies have been applied to the dairy industry to reuse the water in its processes and to improve the quality of the products. Vourch et al. (2005) treated a diluted skimmed milk to study the combination of a single reverse osmosis or nanofiltration plus reverse osmosis operations for water reuse.

Whey is the main by-product obtained from cheese production. It contains a high concentration of organic matter, mainly proteins and lactose. Due to the added value of these compounds, they can be used in the food industry (e.g., infant and dietetic food, bakery products). However, whey's high salt content makes it neces-

Received July 17, 2006.

Accepted November 6, 2006.

${ }^{1}$ Corresponding author: beacuau1@iqn.upv.es sary to first perform a demineralization. Concentration and demineralization of whey have been important applications for membrane technologies in the dairy industries (Van der Horst et al., 1995; Räsänen et al., 2002). Nanofiltration processes have been studied to reduce the losses of lactose and to improve the capability to demineralize whey (Jeantet et al., 1996; Mucchetti et al., 2000; Atra et al., 2005).

In general, nanofiltration membranes are characterized by rejection of mainly divalent and multivalent ions. In these membranes, monovalent ion rejection are usually low depending on feed concentration and membrane characteristics (Freger et al., 2000). According to the manufacturer (GE-Osmonics, Herentals, Belgium), the DS-5 DL membrane is characterized by rejecting preferentially divalent and multivalent ions, whereas rejection of monovalent ions is dependent upon both feed concentration and composition. Because monovalent ions pass through the membrane, the osmotic pressure difference across the membrane is low. The main characteristic of the NF200 membrane (Dow Chemical Co., Minneapolis, MN) is high productivity with a partial softening to maintain a minimum level of hardness.

Because nanofiltration can separate low molecular weight solutes from mineral salt solutions, the technique is very attractive for industrial applications in the food (e.g., milk concentration, whey demineralization) and pharmaceutical industries. Although the separation mechanisms are not clear, they determined by complex steric and electrical effects or electroneutrality principle (Donnan effect; Xu and Spencer, 1997). In addition, the behavior of a nano-filtration membrane is influenced by the feed solution characteristics (Mohammad and Takriff, 2003) and by the membrane material properties, including hydrophobicity, isoelectric point, and type of solute.

Several studies have been carried out to determine the main factors affecting membrane behavior in terms of volumetric flux and selectivity (Mohammad and Takriff, 2003; Tanninen and Nyström, 2002; Qin et al., 2004). Mohammad and Takriff (2003) and Tanninen and Nyström (2002) reported the influence of $\mathrm{pH}$, concluding that the membrane is less negatively charged in the presence of salts due to the adsorption of charged 


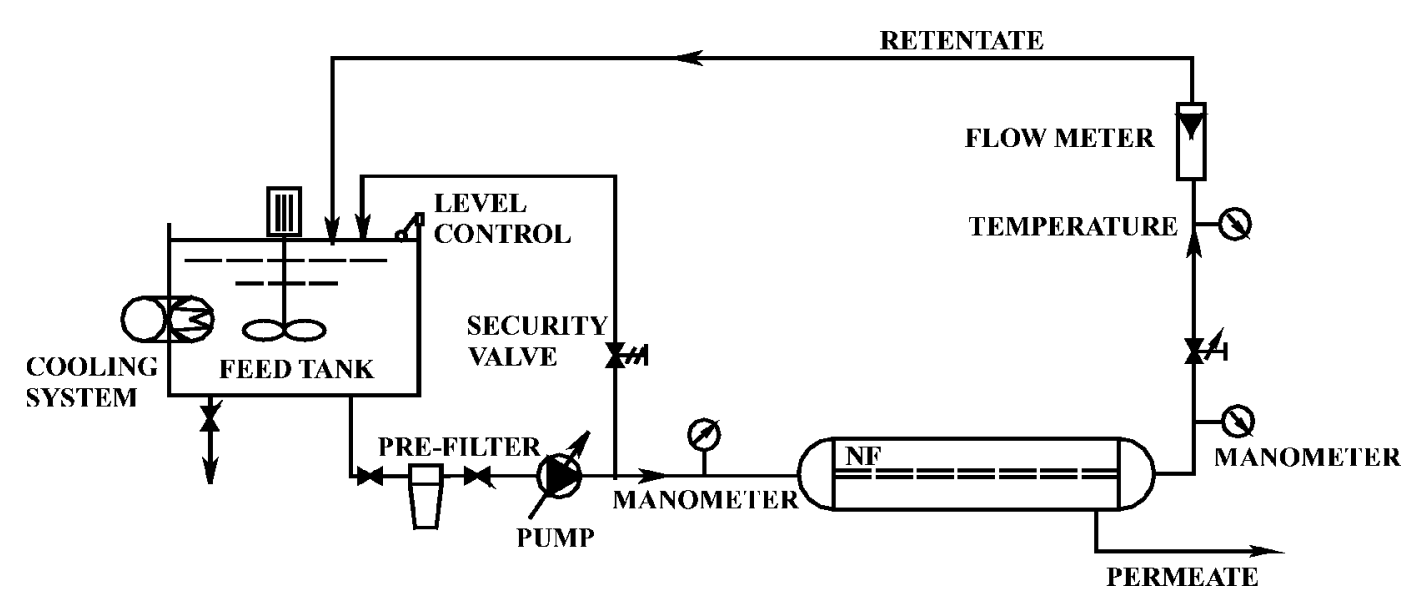

Figure 1. Diagram of the nanofiltration (NF) laboratory plant.

solutes and the disassociation of functional groups present in the membrane polymeric net. Deshmukh and Childress (2001) and Shim et al. (2002) indicated that the presence of counter ions such as calcium, magnesium, potassium, and sodium in the feed could decrease the zeta potential. Teixeira et al. (2005) and Tay et al. (2002) investigated the influence of salt type and $\mathrm{pH}$ on the membrane charge. These works showed that the membrane charge and the fitted mean pore size depend on the salt under study.

Membrane fouling is the most common drawback of the nanofiltration process. In the case of whey filtration, compounds that can contribute to membrane fouling are proteins such as caseins, $\alpha$-LA, and $\beta$-LG and other organic compounds such as fats, because all these compounds can be adsorbed on the membrane and clog the pores. In addition, calcium and phosphate ions can cause severe fouling (Alkhatim et al., 1998; Tay et al., 2002), increasing the treatment cost in terms of cleaning processes or membrane replacement. To avoid fouling problems, some authors studied whey ultrafiltration before nanofiltration and chose nanofiltration membranes with hydrophilic characteristics (Rektor and Vatai, 2004; Atra et al., 2005).

Table 1. Ultrafiltered whey characterization ${ }^{1}$

\begin{tabular}{lc}
\hline Component & Concentration, g/L \\
\hline Total protein & 2.0 to 2.2 \\
Lactose & 41.9 to 52.0 \\
Fat & 0.0 \\
Chlorides & 1.08 to 1.29 \\
Sodium & 0.35 to 0.37 \\
Potassium & 1.40 to 1.48 \\
Magnesium & 0.07 to 0.09 \\
Sulfates & 0.09 to 0.12 \\
Phosphates & 0.51 to 0.60 \\
\hline
\end{tabular}

${ }^{1}$ Feed $\mathrm{pH}=6.10$ to 6.50 and $\kappa$ (conductivity) $=4.6$ to $5.9 \mathrm{mS} / \mathrm{cm}$.
In this work, the treatment of a highly polluting effluent that comes from the Spanish cheese industry is studied. The total volume of whey in this industry represents almost $83 \%$ of the total generated waste stream. The main objective of this research was to compare 2 nanofiltration membranes to demineralize an ultrafiltered (UF) whey. In this case, demineralization with nanofiltration membranes consisted of separating monovalent salts (permeate stream) from the rest of the compounds (lactose and polyvalent ions) contained in the UF whey (rejection stream). The membrane selection criteria were salt rejection, volumetric and solute fluxes, and membrane characteristics (isoelectric point, cut-off, pore radii, thickness, contact angle, and zeta potential).

\section{MATERIALS AND METHODS}

\section{Feed Characterization}

The whey samples supplied by the dairy industry were previously ultrafiltered to avoid fouling in the nanofiltration process. Feed (UF whey) was analyzed by the following analytical methods: fat content was analyzed using the Gerber method (UNE 34-898-86) and N concentration was determined by means of the Kjeldahl method (UNE EN ISO 8968-2/3; Alkatim et al., 1998). To estimate the protein content, the calculated total Kjeldahl $\mathrm{N}$ was multiplied by 6.38 . Lactose concentration and dry extract were determined according to standard procedures UNE 34-826-83 and UNE 34-824-83, respectively (Alkatim et al., 1998). Ions were analyzed by a chromatographic method (American Public Health Association, 1989) using a Metrohm 790 Personal Ion chromatograph (Metrohm, Herisau, Switzerland). For the determination of conductivity and $\mathrm{pH}$, a Crison ap- 
Table 2. Membrane characteristics according to membrane manufacturer and literature data

\begin{tabular}{lcc}
\hline & \multicolumn{2}{c}{ Membrane } \\
\cline { 2 - 3 } Characteristic & DS-5 DL & NF200 \\
\hline Manufacturer & GE-Osmonics & Dow Chemical \\
Element (membrane module) & 2,540 & 2,540 \\
Membrane surface, $\mathrm{m}^{2}$ & 2.51 & 2.60 \\
Molecular weight cutoff, Da & 150 to 300 & 200 to 300 \\
Maximum pressure, $\mathrm{MPa}$ & 3.45 & 4.1 \\
Maximum temperature, ${ }^{\circ} \mathrm{C}$ & 50 & 45 \\
pH tolerance & 2 to 11 & 3 to 10 \\
Isoelectric point pH & $4.0^{1}$ & $4.3($ manufacturer $)$ \\
Zeta potential, mV & $-5^{1}$ & $-16.5(\mathrm{pH}=7)^{2}$ \\
Contact angle, degree $\left(^{\circ}\right)$ & $42^{1}$ & $30.3^{3}$ \\
\hline
\end{tabular}

${ }^{1}$ Nyström et al., 2004.

${ }^{2}$ Her et al., 2000.

${ }^{3}$ Bellona and Drewes, 2005.

paratus (Barcelona, Spain) with temperature compensation was used.

Table 1 shows the characterization of the UF whey. This stream was the feed for both membranes. The UF whey did not contain fat and its protein concentration was low $(2.0$ to $2.2 \mathrm{~g} / \mathrm{L})$. It can be observed that the conductivity was high, mainly due to potassium and chloride ion concentrations.

\section{Nanofiltration Experiments}

Membrane experiments were performed in a pilot plant designed in the Polytechnic University of Valencia equipped with a pressure vessel that contains one spiral-wound membrane element (Figure 1). The operating conditions were as follows: transmembrane pressures ranging from 0.5 to $2.5 \mathrm{MPa}$; a feed flow rate of $400 \mathrm{~L} / \mathrm{h}$; and a temperature of 16 to $18^{\circ} \mathrm{C}$; $\mathrm{pH}$ was not adjusted during the experiments. Permeate and reject streams were returned to the feed tank to maintain a constant feed concentration. All experiments were duplicated to validate the experimental results.

Volumetric fluxes $\left(J_{\mathrm{v}}, \mathrm{L} / \mathrm{m}^{2} \mathrm{~h}\right)$ and different solute rejections $\left[\mathrm{R}, \%\right.$; calculated as $\left(1-\mathrm{C}_{\mathrm{P}} / \mathrm{C}_{\mathrm{F}}\right) \times 100$, where
$\mathrm{C}_{\mathrm{P}}$ and $\mathrm{C}_{\mathrm{F}}$ are the solute concentrations in the permeate and feed streams, respectively] were measured when the steady state was achieved. Permeates were analyzed with the same analytical methods used for the feed stream under steady-state conditions. The operating time for each experiment was about $4 \mathrm{~h}$.

The membranes tested were the NF200 (Dow Chemical) and the DS-5 DL (GE Osmonics). Table 2 details the main membrane characteristics according to membrane manufacturer and literature data. Table 3 indicates the mean pore radius, thickness/porosity ratio, rejection data, and water permeability obtained in this work.

The pore radius and the thickness/porosity of the membranes were determined by fitting the experimental data of a pure lactose solution (uncharged solute) by the Donnan steric partioning model (DSPM; Xu and Spencer, 1997; Labbez et al., 2002). These parameters were calculated using the equations included in a previous paper (Cuartas-Uribe et al., 2006). This model is a useful tool that describes the transport phenomena across nanofiltration membranes related to the membrane morphological structure. Bargeman et al. (2005) characterized the DS-5 DL membrane with a glucose solution and found a mean pore radius value of 0.45 $\mathrm{nm}$. Comparing that value with the one obtained in this work with a lactose solution, the differences are negligible, as it can be seen in Table 3 .

Both membranes tested have similar cut-off and isoelectric point values. Previous studies (Her et al., 2000; Nyström et al., 2004; Bellona and Drewes, 2005) reported similar contact angles for the membranes. Because contact angle is related to the membrane hydrophobicity, it can be considered that both membranes are more hydrophilic than hydrophobic.

\section{RESULTS AND DISCUSSION}

\section{Nanofiltration Experiments}

Volumetric Flux. The influence of transmembrane pressure on the volumetric flux under steady-state con-

Table 3. Membrane characteristics obtained in the present work

\begin{tabular}{|c|c|c|}
\hline \multirow[b]{2}{*}{ Characteristic } & \multicolumn{2}{|c|}{ Membrane $^{1}$} \\
\hline & DS-5 DL & NF200 \\
\hline Mean pore radii, $\mathrm{nm}$ & 0.47 & 0.41 \\
\hline Thickness/porosity, $\mu \mathrm{m}$ & 2.84 & 1.81 \\
\hline Solute rejection: lactose ${ }^{2}(50 \mathrm{~g} / \mathrm{L})$ at $22^{\circ} \mathrm{C}, \%$ & 97 to 98 & 98 to 99 \\
\hline Solute rejection: $\mathrm{NaCl}^{2}(1.20 \mathrm{~g} / \mathrm{L})$ at $22^{\circ} \mathrm{C}, \%$ & 29 to 42 & 31 to 38 \\
\hline Water permeability coefficient, $\mathrm{L} /\left(\mathrm{m}^{2} \cdot \mathrm{h} \cdot \mathrm{MPa}\right)$ at $22^{\circ} \mathrm{C}$ & 36 & 44 \\
\hline
\end{tabular}

${ }^{1}$ NF200 membrane (Dow Chemical, Minneapolis, MN); DS-5 DL membrane (GE-Osmonics, Herentals, Belgium).

${ }^{2}$ Single solution containing only water and a solute. 


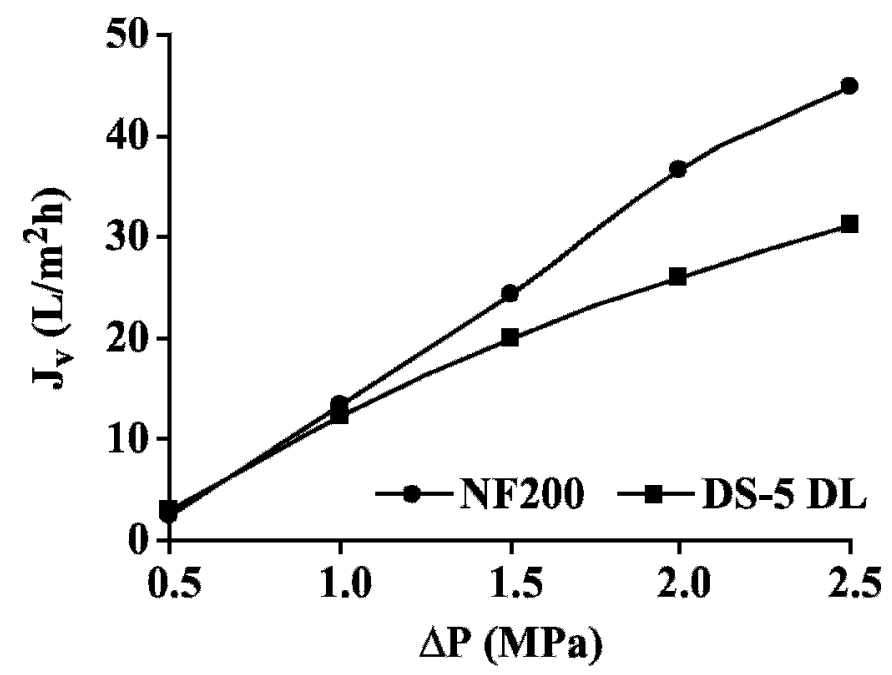

Figure 2. Influence of the transmembrane pressure $(\Delta \mathrm{P})$ on volumetric flux, $J_{\mathrm{v}}$, with the NF200 and DS-5 DL membranes.

ditions is shown in Figure 2. For both membranes, the data fitted the classical models (Kedem-Spiegler and osmotic pressure, among others) in which osmotic pressure differences dominate at low pressures $(<1.5 \mathrm{MPa})$ and concentration polarization dominates at highest pressures ( $>1.5 \mathrm{MPa})$.

However, the flux differences between both membranes can be explained by the thickness/porosity ratio and the fitted pore size, because these values were lower for the NF200 membrane, as can be observed in Table
3. Nyström et al. (2004) and Her et al. (2000) analyzed the layers of both membranes, finding 3 and 4 layers for the NF200 and DS-5 DL, respectively. Nevertheless, the polysulfone microporous layer and polyester nonwoven layer of the support are similar in both membranes. Her et al. (2000) concluded that the high water permeability coefficient of NF200 was because its layers provide maximum strength and compression resistance combined with minimum resistance to permeate flow.

Although NF200 had a higher water permeability coefficient (Table 3 ), the volumetric flux was very similar to that of the DS-5 DL membrane at transmembrane pressures lower than 1.5 MPa. This can be explained by the influence of the osmotic pressure on the volumetric flux. The osmotic pressure difference for NF200 was higher because this membrane presented the highest solute rejection for all tested ions (Figure 3).

Rejection. Figures 3 and 4 depict the influence of the transmembrane pressure on ion rejections for both membranes. In general, it can be observed that increasing the transmembrane pressure increased ion rejections. At pressures above $1.5 \mathrm{MPa}$, ion rejections remained almost constant for each membrane.

With regard to monovalent ions, NF200 presented higher rejection values than DS-5 DL $(80 \%$ and $<30 \%$, respectively); some negative rejection values were achieved for DS-5 DL. This fact can be explained by the Donnan effect in which the chloride ions pass through the membrane in higher proportions to ensure the electroneutrality of the permeate stream. This behavior has been observed by other authors (Gilron et
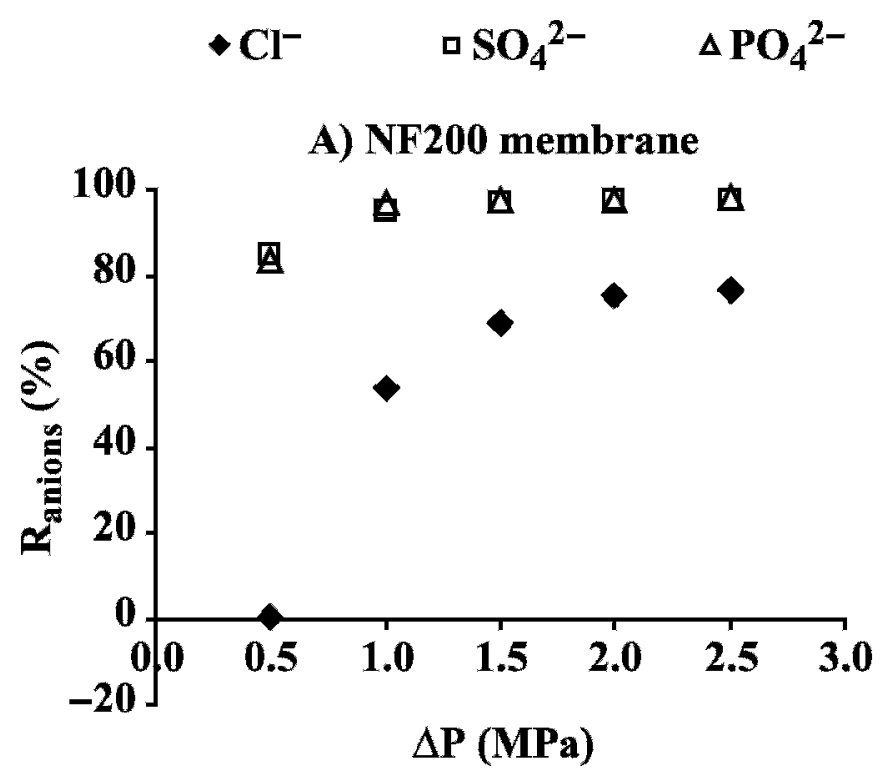

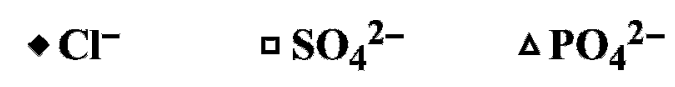

B) DS-5 DL membrane

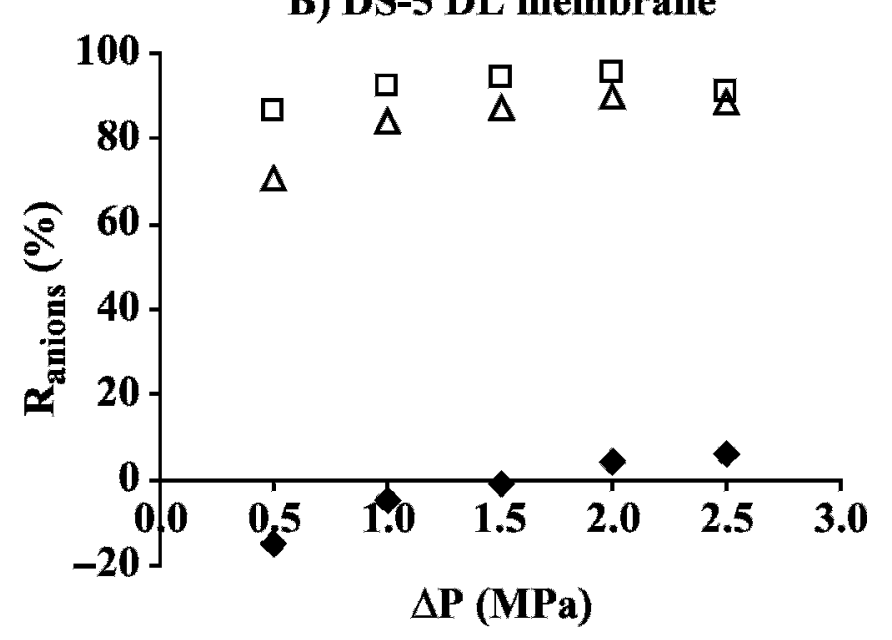

Figure 3. Influence of the transmembrane pressure $(\Delta \mathrm{P})$ on anion rejections $(\mathrm{R})$, with the NF200 and DS-5 DL membranes. 


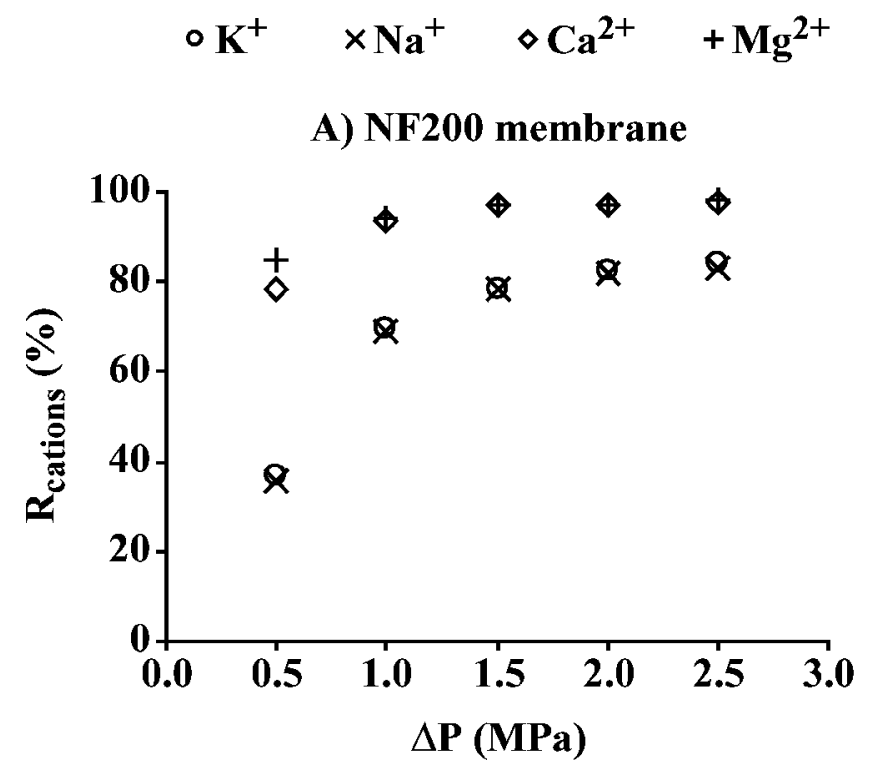

$\circ \mathrm{K}^{+} \quad \times \mathrm{Na}^{+} \quad \diamond \mathrm{Ca}^{2+}+\mathrm{Mg}^{2+}$

B) DS-5 DL membrane

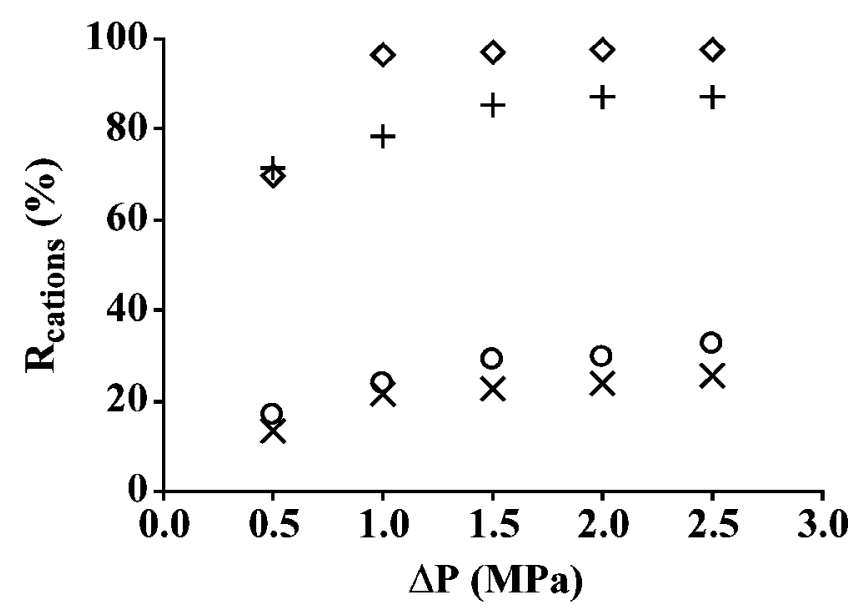

Figure 4. Influence of the transmembrane pressure $(\Delta \mathrm{P})$ on cation rejections $(\mathrm{R})$, with the NF200 and DS-5 DL membranes.

al., 2001; Szoke et al., 2002). However, the NF200 membrane did not behave in this way. This can be explained by both a higher zeta potential value of $-16 \mathrm{mV}$ (entailing more electrostatic repulsion of coions than DS-5 DL) and its pore radii size, which made it difficult for chloride ions to pass through the membrane.

On the contrary, the rejection value differences for polyvalent ions were negligible for both membranes. Thus, the rejection values ranged from 90 to $100 \%$.

With regard to hydration enthalpy and hydrated radii (Table 4), the theoretical rejection sequence for the ions should be as follows: $\mathrm{Mg}^{2+}>\mathrm{Ca}^{2+}>\mathrm{SO}_{4}{ }^{2-}>\mathrm{Na}^{+}>\mathrm{Cl}^{-}$ $>\mathrm{K}^{+}$. However, experimental results showed the following sequence: $\mathrm{PO}_{4}{ }^{3-} \cong \mathrm{SO}_{4}{ }^{2-}>\mathrm{Mg}^{2+} \cong \mathrm{Ca}^{2+}>\mathrm{Na}^{+} \cong \mathrm{K}^{+}$ $>\mathrm{Cl}^{-}$. These results can be explained by the steric effect (Marcus, 1985) and by the Donnan exclusion mechanism as reported in similar studies (Afonso and de Pinho, 2000; Labbez et al., 2003).

Table 4. Steric characteristics of ions (Marcus, 1985)

\begin{tabular}{lccc}
\hline Ion & $\begin{array}{c}\text { Ionic } \\
\text { radius, } \mathrm{nm}\end{array}$ & $\begin{array}{c}\text { Hydrated } \\
\text { radius, nm }\end{array}$ & $\begin{array}{c}\text { Hydration } \\
\text { enthalpy, kJ/mol }\end{array}$ \\
\hline $\mathrm{PO}_{4}^{3-}$ & 0.249 & - & - \\
$\mathrm{SO}_{4}^{2-}$ & 0.230 & 0.379 & $-1,138$ \\
$\mathrm{Ca}^{2+}$ & 0.099 & 0.412 & $-1,577$ \\
$\mathrm{~K}^{+}$ & 0.133 & 0.331 & -324 \\
$\mathrm{Cl}^{-}$ & 0.181 & 0.332 & -376 \\
$\mathrm{Mg}^{2+}$ & 0.065 & 0.428 & $-1,931$ \\
$\mathrm{Na}^{+}$ & 0.095 & 0.358 & -407 \\
\hline
\end{tabular}

Because the tested membranes have a negative charge at feed $\mathrm{pH}, \mathrm{Cl}^{-}, \mathrm{SO}_{4}{ }^{2-}$, and $\mathrm{PO}_{4}{ }^{3-}$ are coions and $\mathrm{Na}^{+}, \mathrm{K}^{+}, \mathrm{Ca}^{+2}$, and $\mathrm{Mg}^{+2}$ are the counter ions relative to the charge sign of the membrane. Therefore, the higher the coion valence, the higher the rejection. In the same way, the rejection of the counter ions for the highest valence is lower than for sulfate and phosphate $\diamond$ DS-5 DL

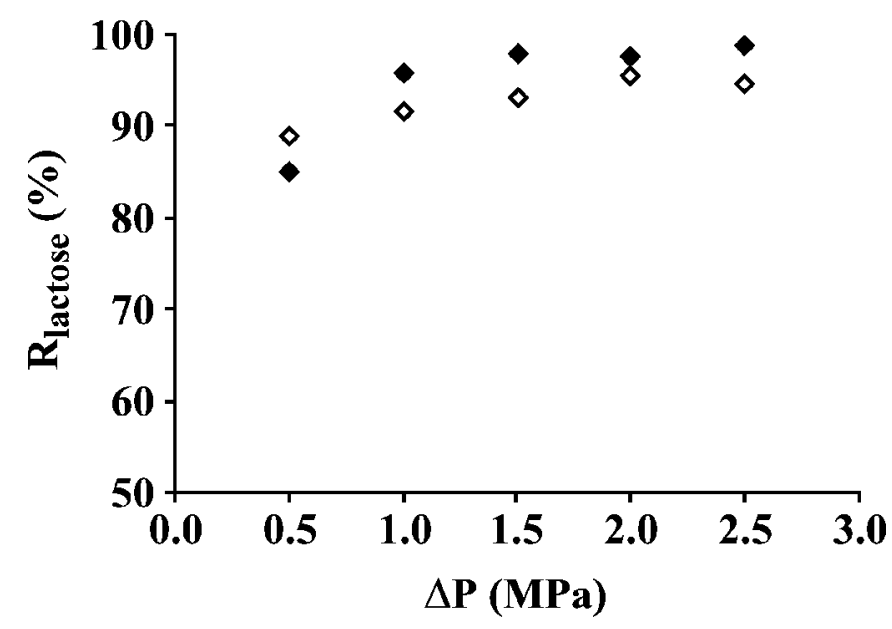

Figure 5. Influence of the transmembrane pressure $(\Delta \mathrm{P})$ on lactose rejections (R), with the NF200 and DS-5 DL membranes. 
Table 5. Flux of lactose and monovalent ions (mean \pm SD) for NF200 and DS-5 DL membranes ${ }^{1}$

\begin{tabular}{|c|c|c|c|c|c|c|c|c|}
\hline \multirow{3}{*}{$\begin{array}{l}\Delta \mathrm{P},{ }^{2} \\
\mathrm{MPa}\end{array}$} & \multicolumn{8}{|c|}{ Solute flux $\left(\mathrm{g} / \mathrm{m}^{2} \mathrm{~h}\right)$} \\
\hline & \multicolumn{2}{|c|}{ Lactose } & \multicolumn{2}{|c|}{$\mathrm{Cl}^{-}$} & \multicolumn{2}{|c|}{$\mathrm{Na}^{+}$} & \multicolumn{2}{|c|}{$\mathrm{K}^{+}$} \\
\hline & NF200 & DS-5 DL & NF200 & DS-5 DL & NF200 & DS-5 DL & NF200 & DS-5 DL \\
\hline 1.0 & $30.43 \pm 2.16$ & $44.76 \pm 3.24$ & $6.90 \pm 0.70$ & $16.92 \pm 1.21$ & $1.52 \pm 0.38$ & $3.66 \pm 0.51$ & $5.91 \pm 0.89$ & $14.14 \pm 0.51$ \\
\hline 1.5 & $27.28 \pm 1.59$ & $58.23 \pm 0.95$ & $8.44 \pm 0.71$ & $26.53 \pm 2.80$ & $1.92 \pm 0.38$ & $5.84 \pm 0.76$ & $7.43 \pm 0.95$ & $21.42 \pm 1.08$ \\
\hline 2.0 & $44.35 \pm 1.27$ & $48.65 \pm 0.95$ & $9.90 \pm 0.64$ & $32.42 \pm 1.02$ & $2.39 \pm 0.32$ & $7.41 \pm 0.38$ & $9.13 \pm 0.95$ & $27.38 \pm 1.59$ \\
\hline
\end{tabular}

${ }^{1}$ NF200 membrane (Dow Chemical, Minneapolis, MN); DS-5 DL membrane (GE-Osmonics, Herentals, Belgium).

${ }^{2}$ Transmembrane pressure.

coions. The ion rejection sequence obtained is explained by this reasoning.

Lactose rejection values (Figure 5) were slightly higher for NF200 than for DS-5 DL (98\% and 95\%, respectively). These values were slightly lower (1 to $2 \%$ ) compared with those obtained by working with lactose single solutions (see Table 3).

The high diffusive transport of salts through the membrane compared with convective transport explains the low rejection values at low volumetric fluxes. Nevertheless, at high volumetric flux, the convective transport becomes more important and rejection increases (Van der Horst et al., 1995; Cuartas et al., 2004).

Solute Flux. Tables 5 and 6 show the solute flux results $\left[\mathrm{g} /\left(\mathrm{m}^{2} \cdot \mathrm{h}\right)\right]$ for all solutes, calculated as the product $J_{v} \times(1-R) \times C_{F}$, for NF200 and DS-5 DL, respectively. This parameter is key to determining demineralization rates. In this way, volumetric fluxes and rejection values have to be considered.

The maximum lactose flux was achieved at $2 \mathrm{MPa}$ for the NF200 membrane. It was due to the maximum increase of the slope variation of the volumetric flux (Figure 2). For DS-5 DL, 2 maximum flux values were obtained at 1.5 and $2.5 \mathrm{MPa}$, achieving 58.23 and 72.42 $\mathrm{g} /\left(\mathrm{m}^{2} \mathrm{~h}\right)$, respectively.
With regard to monovalent ions, the highest solute flux values were achieved for chloride ions; this trend was the same for both membranes. Solute flux values were higher for the DS-5 DL membrane than for the NF200 membrane. For instance, the results obtained at $1.5 \mathrm{MPa}$ for chloride ion flux were 8.44 and $26.53 \mathrm{~g} /$ $\left(\mathrm{m}^{2} \mathrm{~h}\right)$ for NF200 and DS-5 DL, respectively, as shown in Table 5.

As expected, the solute flux for polyvalent ions was very low due to the nanofiltration membrane characteristics, as can be observed in Table 6. In general, solute flux increased with the pressure applied. However, the lowest values were obtained with magnesium cation because the steric hindrance value (difficulty of passing through the membrane pores) is more important than for the rest of cations (Childress, 1996).

According to the results obtained, the solute flux values sequence for both membranes was as follows for all the transmembrane pressures tested: Lactose $>\mathrm{Cl}^{-} \cong$ $\mathrm{K}^{+}>\mathrm{Na}^{+}>\mathrm{PO}_{4}{ }^{3-}>\mathrm{Ca}^{2+}>\mathrm{SO}_{4}{ }^{2-} \cong \mathrm{Mg}^{2+}$.

In summary, related to the overall demineralization, the best results were obtained with the DS- 5 DL membrane at $2 \mathrm{MPa}$, as can be observed in Table 5. Table 7 shows the characteristics of the UF whey (feed) and the permeate stream after being nanofiltered. Taking

Table 6. Flux of polyvalent ions for NF200 and DS-5 DL membranes ${ }^{1}$

\begin{tabular}{|c|c|c|c|c|c|c|c|c|}
\hline \multirow{3}{*}{$\begin{array}{l}\Delta \mathrm{P},{ }^{2} \\
\mathrm{MPa}\end{array}$} & \multicolumn{8}{|c|}{ Flux $\left(g / m^{2} h\right)$} \\
\hline & \multicolumn{2}{|c|}{$\mathrm{PO}_{4}^{3-}$} & \multicolumn{2}{|c|}{$\mathrm{SO}_{4}^{2-}$} & \multicolumn{2}{|c|}{$\mathrm{Ca}^{2+}$} & \multicolumn{2}{|c|}{$\mathrm{Mg}^{2+}$} \\
\hline & NF200 & DS-5 DL & NF200 & DS-5 DL & NF200 & DS-5 DL & NF200 & DS-5 DL \\
\hline 0.5 & 0.25 & 0.61 & 0.06 & 0.04 & 0.19 & 0.26 & 0.04 & 0.07 \\
\hline 1.0 & 0.23 & 1.19 & 0.09 & 0.09 & 0.26 & 0.66 & 0.07 & 0.20 \\
\hline 1.5 & 0.29 & 1.58 & 0.09 & 0.11 & 0.23 & 0.89 & 0.06 & 0.22 \\
\hline 2.0 & 0.47 & 1.64 & 0.12 & 0.12 & 0.32 & 0.96 & 0.09 & 0.25 \\
\hline 2.5 & 0.46 & 2.12 & 0.13 & 0.26 & 0.30 & 1.19 & 0.07 & 0.28 \\
\hline
\end{tabular}


Table 7. Characterization of UF whey and nanofiltered permeate using the DS-5 DL membrane ${ }^{1}$

\begin{tabular}{lcc}
\hline Parameter & $\begin{array}{c}\text { UF } \\
\text { whey }\end{array}$ & $\begin{array}{c}\text { Nanofiltered } \\
\text { permeate }\end{array}$ \\
\hline Total protein, g/L & 2.1 & 0.0 \\
Lactose, g/L & 41.9 & 1.9 \\
Fat, g/L & 0.0 & 0.0 \\
Chlorides, gL & 1.29 & 1.23 \\
Sodium, g/L & 0.37 & 0.28 \\
Potassium, g/L & 1.48 & 1.04 \\
Magnesium, g/L & 0.072 & 0.009 \\
Sulfates, g/L & 0.093 & 0.004 \\
Phosphates, g/L & 0.60 & 0.062 \\
pH & 6.3 & 6.2 \\
Conductivity $(\kappa), \mathrm{mS} / \mathrm{cm}$ & 5.8 & 4.8 \\
\hline
\end{tabular}

${ }^{1}$ Operating conditions: transmembrane pressure $=2 \mathrm{MPa}$, feed flow rate $=400 \mathrm{~L} / \mathrm{h} \kappa$.

into account the conductivity values between both streams, the overall demineralization (i.e., mineral salt content removed from the feed stream) was $17 \%$.

\section{CONCLUSIONS}

The tested membranes did not completely demineralize the whey. The best results were obtained with the DS-5 DL membrane. In this case, the chloride ion rejections were negligible due to the Donnan effect. For the rest of the monovalent ions, rejection was between 20 and $30 \%$. Lactose rejections were approximately $96 \%$ at transmembrane pressures above $1.5 \mathrm{MPa}$.

For the NF200 membrane, high rejection and permeability values were obtained because of low pore radius size, the thin selective layer, negative zeta potential, and the predominant osmotic pressure (related to the ionic strength) on these parameters. It should be noted that NF200 did not demineralize the whey because higher rejection values were achieved for monovalent and polyvalent ions. However, high ion rejection was only achieved for polyvalent ions with the DS-5 DL membrane. Because the whey was previously ultrafiltered and the membranes were hydrophilic, according to the contact angle values, no fouling problems were observed during the tests. It can be concluded that the DS-5 DL membrane is more appropriate than the NF200 membrane for the demineralization of the tested sweet whey. To increase the whey demineralization and lactose concentration, further experiments involving an additional step based on concentration and diafiltration would be necessary.

\section{REFERENCES}

Afonso, M. D., and M. N. de Pinho. 2000. Transport of $\mathrm{MgSO}_{4}, \mathrm{MgCl}_{2}$ and $\mathrm{Na}_{2} \mathrm{SO}_{4}$ across an amphoteric nanofiltration membranes. J. Memb. Sci. 179:137-154.
Alkhatim, H. S., M. I. Alcaina, E. Soriano, J. Lora, and J. Arnal. 1998. Treatment of whey effluents from dairy industries by nanofiltration membranes. Desalination 119:177-184.

American Public Health Association, American Water Works Association, Water Pollution Control Federation. 1989. Standard methods: For the examination of water and wastewater. L. S. Clesceri, A. E. Greenberg, R. R. Trussell, and M. A. H. Franson, ed. APHA, New York, NY.

Atra, R., G. Vatai, E. Bekassy-Molnar, and A. Balint. 2005. Investigation of ultra- and nanofiltration for utilization of whey protein and lactose. J. Food Eng. 67:325-332.

Bargeman, G., J. M. Vollenbroek, J. Straatsma, C. G. P. H. Schroën, and R. M. Boom. Nanofiltration of multi-component feeds. 2005. Interactions between neutral and charged components and their effect on retention. J. Memb. Sci. 247:11-20.

Bellona, C., and J. E. Drewes. 2005. The role of membrane surface charge and solute physico-chemical properties in the rejection of organic acids by NF membranes. J. Memb. Sci. 249:227-234.

Childress, A. E. 1996. Effect of solution chemistry on the surface charge of polymeric reverse osmosis and nanofiltration membranes. J. Memb. Sci. 119:253-268.

Cuartas, B., M. I. Alcaina, and E. Soriano. 2004. Separation of mineral salts and lactose solutions through nanofiltration membranes. Food Sci. Technol. Int. 10:255-262.

Cuartas-Uribe, B., M. C. Vicent-Vela, S. Álvarez-Blanco, M. I. Alcaina-Miranda, and E. Soriano. 2006. Prediction of solute rejection in nanofiltration processes using different mathematical models. Desalination 200:144-145.

Deshmukh, S. S., and A. E. Childress. 2001. Zeta potential of commercial RO membranes: Influence of source water type and chemistry. Desalination 140:87-95.

Freger, V., T. C. Arnot, and J. A. Howell. 2000. Separation of concentrated organic/ionorganic salt mixtures by nanofiltration. J. Memb. Sci. 178:185-193.

Her, N. G., G. Amy, and C. Jarusutthirak. 2000. Seasonal variations of nanofiltration (NF) foulants: Identification and control. Desalination 132:143-160.

Gilron, J., N. Gara, and O. Kedem. 2001. Experimental analysis of negative salt rejection in nanofiltration membranes. J. Memb. Sci. 185:223-236.

Jeantet, R., P. Schuck, M. H. Famelart, and J. L. Maubois. 1996. Intérêt de la nanofiltration dans la production de poundres de lactosérum déminéralisées. Lait 76:283-301.

Labbez, C., P. Fievet, A. Szymczyk, F. Thomas, A. Vidonne, J. Pagetti, and A. Foissy. 2002. A comparison of membrane charge of a low nanofiltration ceramic membrane determined from ionic retention and tangential streaming potential measurements. Desalination 147:223-229.

Labbez, C., P. Fievet, A. Szymczyk, A. Vidonne, A. Foissy, and J. Pagetti. 2003. Retention of mineral salts by a polyamide nanofiltration membrane. Sep. Purif. Technol. 30:47-55.

Marcus, Y. 1985. Ion solvation. Wiley, New York, NY

Mohammad, A. W., and M. S. Takriff. 2003. Predicting flux and rejection of multicomponent salts mixture in nanofiltration membranes. Desalination 157:105-111.

Mucchetti, G., G. Zardi, F. Orlandini, and C. Gostoli. 2000. The preconcentration of milk bynanofiltration in the production of Quargtype fresh cheeses. Lait 80:43-50.

Nyström, M., S. Butylina, and S. Platt. 2004. NF retention and critical flux of small hydrophilic/hydrophobic molecules. Memb. Technol. 10:5-8.

Qin, J. J., M. H. Oo, H. Lee, and B. Coniglio. 2004. Effect of feed pH on permeate $\mathrm{pH}$ and ion rejection under conditions in NF process. J. Memb. Sci. 231:153-159.

Räsänen, E., M. Nyström, J. Sahlstein, and O. Tossavainen. 2002. Comparison of commercial membranes in nanofiltration of sweet whey. Lait 82:343-356.

Rektor, A., and G. Vatai. 2004. Membrane filtration of Mozzarella whey. Desalination 162:279-286.

Shim, Y., H. G. Lee, S. Lee, S. H. Moon, and J. Cho. 2002. Effects of NOM and ionic species on membrane surface charge. Environ. Sci. Technol. 36:3864-3871. 
Szoke, S., G. Patzay, and L. Weiser. 2002. Characteristics of thinfilm nanofiltration membranas at various $\mathrm{pH}$-values. Desalination 151:123-129.

Tanninen, J., and M. Nyström. 2002. Separation of ions in acidic conditions using NF. Desalination 147:295-299.

Tay, J. H., J. Liu, and D. D. Sun. 2002. Effect of solution physicochemistry on the charge property of nanofiltration membranes. Water Res. 36:585-598.

Teixeira, M. R., M. J. Rosa, and M. Nyström. 2005. The role of membrane charge on nanofiltration performance. J. Memb. Sci. 265:160-166.
Van der Horst, H. C., J. M. K. Timmer, T. Robbertsen, and J. Leenders. 1995. Use of nanofiltration for concentration and demineralization in the dairy industry: Model for mass transport. J. Memb. Sci. 104:205-218.

Vourch, M. B., B. Balannec, B. Chaufer, and G. Dorange. 2005. Nanofiltration and reverse osmosis of model process waters from the dairy industry to produce water for reuse. Desalination 172:245-256.

Xu, X., and H. G. Spencer. 1997. Transport of electrolytes through a weak acid nanofiltration membrane: Effects of flux and crossflow velocity interpreted using a fine-porous membrane model. Desalination 113:85-93. 